\title{
Consumption of three strong opioids (morphine, oxycodone and fentanyl) in seven European countries during seven years (2003-2009)
}

\author{
Hudec $\mathrm{R}^{1}$, Tisonova $\mathrm{J}^{1}$, Foltan $\mathrm{V}^{2}$, Kristova $\mathrm{V}^{1}$ \\ Department of Pharmacology and Clinical Pharmacology, Faculty of Medicine, Comenius University, \\ Bratislava, Slovakia. dr.hudec@gmail.com
}

\begin{abstract}
Purpose: The aim was to analyse the consumption of selected strong opioid analgesics during a seven-year period of 2003-2009 in order to compare Slovak consumption with that in six other European countries and to determine our position.

Methods: Drug consumption data from the State Institute for Drug Control in Slovak Republic were used. As to the data from other countries, annual health statistics published on websites were used in comparison.

Results: Obviously the consumption of one of studied opioid drugs with transdermal aplication route, particularly fentanyl, tended to increase in all countries during the observed period. Oxycodone tends to yield a rapid increase in consumption as well. As opposed to the latter drugs, the consumption of morphine was decreasing throughout the observed period. The consumption of these drugs in Slovakia remains low (except for that of fentanyl). Conclusion: Our analysis confirmed a clear shift from oral to transdermal therapy as well as usage of newer drugs. Drug consumption data are a relatively new source of information for health research. Our analysis showed increasing trends in fentanyl (patch opioid) consumption in all compared countries as well as an increasing consumption of oxycodone and decreasing consumption of morphine (Fig. 3, Ref. 17). Full Text in PDF www.elis.sk. Key words: morphine, fentanyl, oxycodone, consumption, pain treatment.
\end{abstract}

An appropriate and successful management of pain with opioid analgesics is based on treatment with minimal effective doses at which pain is controlled with minimal adverse effects. Opioids are associated with a wide range of adverse reactions but these can be minimized with careful drug titration and maintenance. A major challenge relating to pain control is polypharmacy and the risk of pharmacokinetic or pharmacodynamic drug-drug interactions (1).

Opioids are the cornerstone in the treatment of severe pain. Although morphine consumption is considered to be an important indicator of progress in pain relief, studies with observational findings report that transdermal opioids provide adequate relief in chronic pain management (2).

The therapeutic use of opioids has increased substantially. Apart from the lack of effectiveness (except for short-term, acute pain) there are multiple adverse consequences including hormonal and immune system effects, abuse and addiction, tolerance, and hyperalgesia. Patients on long-term opioid use have been shown to increase the overall cost of healthcare, disability, rates of surgery, and late opioid use $(3,4)$.

${ }^{1}$ Department of Pharmacology and Clinical Pharmacology, Faculty of Medicine, Comenius University, Bratislava, Slovakia, and ${ }^{2}$ Department of Organization and Management of Pharmacy, Faculty of Pharmacy, Comenius University, Bratislava, Slovakia

Address for correspondence: R. Hudec, MD, PhD, Department of Pharmacology and Clinical Pharmacology, Faculty of Medicine, Comenius University, Spitalska 24, SK-813 72 Bratislava, Slovakia Phone: +421.2.59357229, Fax: +421.2.59357508
Consistent monitoring of analgesic consumption can be helpful in explaining the different treatment approaches to pain. Drug consumption data are an integral part in the evaluation of health quality level (5).

The aim was to analyse the selected consumed opioid analgesics in a seven-year period (2003-2009) and to compare Slovak consumption with that in six other European countries. We can say it is a kind of a picture of our doctors' intention to treat this most common symptom of disease - pain.

Until 1993, Czech Republic had the same drug policy (common state) and Nordic countries are well known as countries with high standard of pain therapy. Mediterranean countries have a different perception of pain implicating a different policy of pain treatment. Therefore we have tried to confirm our hypothesis concerning low consumption in southern countries and to determine the position of Slovakia.

\section{Methods}

Drug consumption data from the Slovak State Institute for Drug Control in Slovak Republic were used. The analysis was based on Defined Daily Doses per 1000 inhabitants per day.

Expression of data as DDD per 1000 inhabitants per day enables a comparison of active substance in different drug products, different packages, various doses, as well as quantities of various substances in equal ATC class. Therefore, this allows an international comparison. 


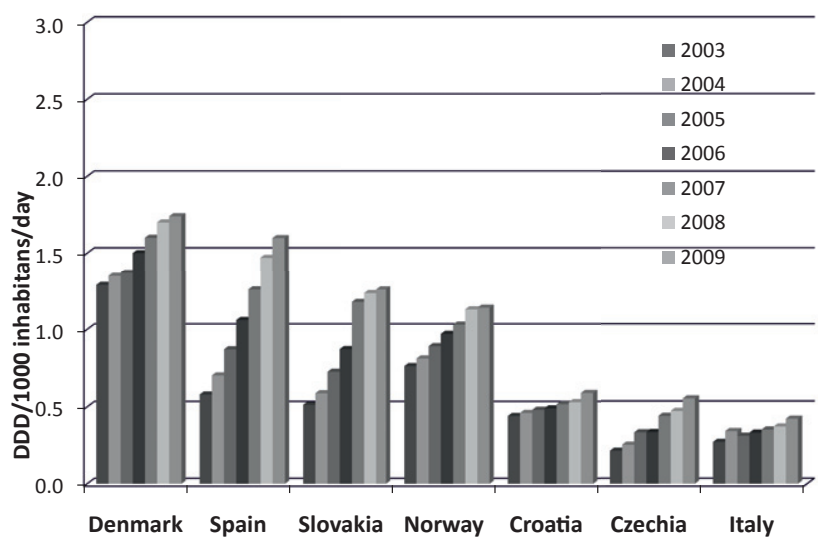

Fig. 1. Consumption of fentanyl in observed countries (expressed as DDD/1000 inhabitans/day).

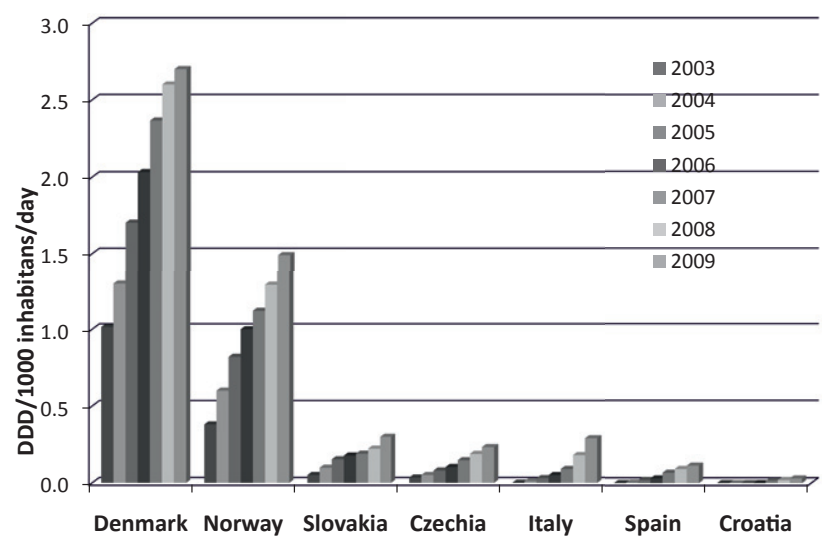

Fig. 2. Consumption of oxycodone in observed countries (expressed as DDD/1000 inhabitans/day).

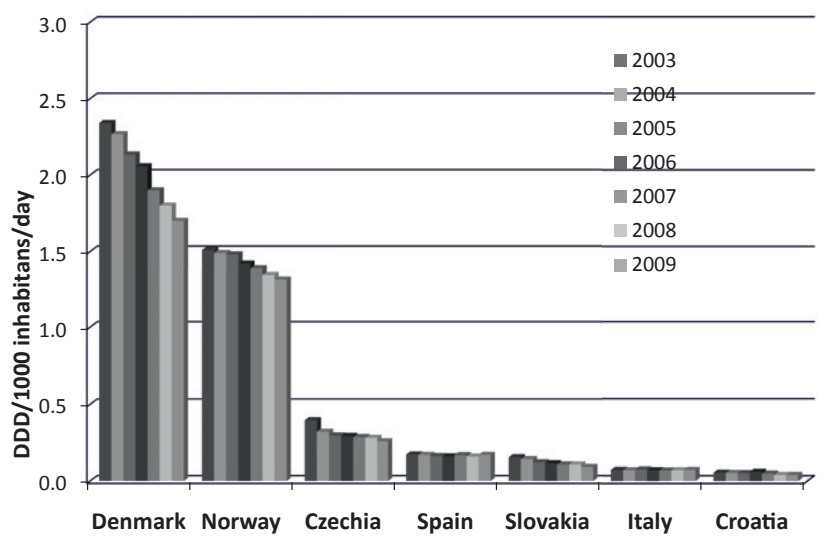

Fig. 3. Consumption of morphine in observed countries (expressed as DDD/1000 inhabitans/day).

In addition to previously published data, annual health statistics of other countries published on websites were used and compared (6-11).
We have selected three strong opioid agonists, particularly fentanyl as a representant of transdermal opioid, oxycodone as a relatively new drug used in therapy of pain, and morphine as a typical opioid analgesic drug (still considered to be the gold standard.

\section{Results}

Obviously the consumption of studied transdermal opioid drug, fentanyl, tends to increase during the observed period. Consumption of this opioid analgesic with transdermal aplication route had an increasing trend in all observed countries (Fig. 1).

The consumption of fentanyl in Slovakia represents one fifth of total opiod consumption which is increasing in all selected countries. Oxycodone tends to have a rapid increase in consumption in all countries as well (Fig. 2).

In contrast to fentanyl and oxycodone, the consumption of morphine is decreasing relatively in comparison to overall consumption in all selected countries (Fig. 3).

The situation in Slovakia and Czech Republic (CR) is very similar with greater consumption of fentanyl and oxycodone in Slovakia and that of morphine in CR.

\section{Discusion}

Fentanyl represents an opioid used in form of a favourably applicable transdermal emplastrum. Morphine is considered to be the gold standard and first-line therapy in the treatment of moderate to severe pain.

Hamunen et al showed that the consumption of opioid analgesics in the Nordic countries changed over a five-year period of 2002-2006 and that it cannot be explained by pharmacology, price, reimbursement or prescription regulations. Marketing has most likely significantly influenced the type and amount of opioids consumed $(12,13)$.

Several studies have documented that the consumption of morphine is decreasing and the vacant place is filled with newer opioid analgesics such as fentanyl $(14,15)$.

The difference between Slovak consumption and consumption in Denmark as well as that in Norway is obvious. Heterogeneity across countries was due to the availability of specific ingredients as well as due to the leading analgesic drug in many countries codeine (14).

The shift from oral therapy to transdermal therapy is clear and our analysis confirmed the data published by Garcia Del Pozo (15). This application form has a better patient compliance as a result of easy non-invasive way of usage.

Observed opioids are used in palliative and terminal forms of care. As we had no access to patient data the detailed inappropriate use in non-malignant pain could not be distinguished.

WHO in their article titled Access to Analgesics and to Other Controlled Medications says: "Severe under-treatment is reported in more than 150 countries, both developing and industrialized, accounting for about $80 \%$ of the world's population. Annually, up to 10 million people suffer from lack of access to controlled medications. Nearly 1 billion of those living today will encounter 
this problem sooner or later. Most of them will be pain patients; others will be suffering from other conditions. The impact of impaired access to these medications is extremely serious" (16).

Drug consumption data are a relatively new source of information for health research. Our analysis showed increasing trends in fentanyl and oxycodone consumption in all compared countries with a decreasing consumption of morphine. Nevertheless, opioid prescribing is often discussed and criticized both for under or overuse.

Our hypothesis, initially stated in our previously published manuscript (17), was confirmed especially concerning morphine as well as oxycodone consumption. The situation in fentanyl consumption has a little difference to it (Spain was among countries with high consumption).

In terms of morphine consumption, Slovakia is a country distinctly different from e.g. Denmark, which ranks first in all observations. The consumption of fentanyl and oxycodone in Slovakia is much better; the difference is not so obvious.

John Milton once said: "Pain is a perfect misery". This especially applies to chronic, malignant pain, in treatment of which strong opioids are used. Therefore the increasing trends in opioids consumption are good.

\section{References}

1. Geppetti P, Benemei S. Pain treatment with opioids : achieving the minimal effective and the minimal interacting dose. Clin Drug Investig 2009; 29 (Suppl 1): 3-16.

2. American Society of Anesthesiologists Task Force on Chronic Pain Management; American Society of Regional Anesthesia and Pain Medicine: Practice guidelines for chronic pain management: an updated report by the American Society of Anesthesiologists Task Force on Chronic Pain Management and the American Society of Regional Anesthesia and Pain Medicine. Anesthesiology 2010; 112 (4): 810-833.

3. Fredheim OM, Skurtveit S, Breivik H et al. Increasing use of opioids from 2004 to 2007 -Pharmacoepidemiological data from a complete national prescription database in Norway. Eur J Pain 2010; 14 (3): 289-294.

4. Manchikanti L, Singh A. Therapeutic opioids: a ten-year perspective on the complexities and complications of the escalating use, abuse, and nonmedical use of opioids. Pain Physician 2008; 11 (Suppl 2): S63-88.
5. Hudec R, Božeková L, Foltán V, et al. 5 most consumpted opioid analgesics in Slovakia in the year 2006 - comparison to five other countries (Finland, Norway, Denmark, Spain, Australia). Bratisl Med J 2009; 110 (5): 316-318.

6. Norwegian Institute of Public Health. Drug consumption in Norway. Available at: http://www.legemiddelforbruk.no Accessed in December 2011.

7. The Danish Medicines Agency. Medicinal Product Statistics in Denmark. Available at: http://www.dkma.dk Accessed in December 2011

8. Czech State Institute for Drug Control. Spotřeba léčiv v České republice v jednotlivých letech. Available at: www.sukl.cz Accessed at December 2011.

9. International Narcotic Control Board; United Nations Demographic Yearbook, available at www.medsch. wisc.edu/Acessed in December 2011.

10. Chinellato A, Skaper SD, Giusti P et al. Consumption of opioid analgesics in Italy: light at the end of the tunnel? Eur J Pain 2011; 15 (2): 220-221.

11. The Agency for Medicinal Products and Medical Devices of Croatia. Annual Reports on Drug Consumption. Available at: www.almp.hr Accessed at December 2011

12. Hamunen K, Paakkari P, Kalso E. Trends in opioid consumption in the Nordic countries 2002-2006. Eur J Pain 2009; 13 (9): 954-962.

13. Hamunen K, Laitinen-Parkkonen P, Paakkari P et al. What do different databases tell about the use of opioids in seven European countries in 2002? Eur J Pain 2008; 12 (6): 705-715.

14. De Conno F, Ripamonti C, Brunelli C. Opioid purchases and expenditures in nine western European countries:"Are we killing of morphine?". Palliat Med 2005; 19 (3): 179-184.

15. Garcia Del Pozo J, Carvajal A, Viloria JM et al. Trends in the consumption of opioid analgesics in Spain. Higher increases as fentanyl replaces morphine. Eur J Clin Pharmacol 2008; 64 (4): 411-415.

16. World Healh Organisation publications. Available at: http://www. who.int/medicines/areas/quality_safety/access_Contr_Med/en/ index. html. Accessed in December 2011.

17. Hudec R, Tisonová J, Bozeková et al. Trends in consumption of opioid analgesics in Slovak Republic during 1998-2002. Eur J Clin Pharmacol 2004; 60 (6): 445-448.

Received December 6, 2011. Accepted July 20, 2013. 